\title{
A capability analysis on the implementation of the school progression policy and its impact on learner performance
}

\section{Paul Munje and Rouaan Maarman}

(Received 17 August 2015; accepted 5 May 2016)

\begin{abstract}
This paper focuses on the extent and consequences of learner progression in the form of 'automatic promotion' or grade promotion for reasons other than academic achievement, as propagated by the existing School Progression Policy (SPP) and how its implementation affects learner performance. The paper argues that, although the advantages and disadvantages of grade retention and automatic promotion, or the promotion of learners that do not possess the required content knowledge, are highly contentious, the SPP produces numerous complexities and unfreedoms on learners when examined through the lens of the Capabilities Approach (CA). Based on a study of three Quintile-1 (Q-1) primary schools in Cape Town, the paper argues that, although the SPP is ambitious and well intentioned, critical implementation and monitoring challenges negatively reconfigures the educational aspirations of primary school learners. The paper also reveals that the implementation of the SPP imposes many unfreedoms for both learners and teachers in high poverty level areas. The study revealed that the CA, despite its limitations in terms of conceptualisation, does provide a unique framework to investigate real freedoms and unfreedoms of the SPP.
\end{abstract}

\section{Statement of the problem}

Although some of the South African government's objectives in the domain of education, such as access have been achieved (Modisaotsile, 2012), others such as finding a balance between enrolment and performance, and between input and outcomes, especially in poor schools, remains an on-going education crisis and debate (Spaull, 2013; Pretorius, 2014). In the view of Maarman (2009), government efforts to improve education have been dampened by existing poverty imperatives, despite acknowledgements of great improvements in the South African education system (Crouch and Mabogoane, 2001; Chisholm, 2004; Van der Berg, 2006; Taylor, Fleisch and Shindler, 2008; Taylor, Van der Berg and Burger, 2012). The current impasse 
of Q-1 primary schools interrogates the efficacy of current policy approaches as there is evidence of persistent poor learner performance. The predicament of poor schools in South Africa is described as worsening and in need of different ways to understand and address the problem (Itumeleng and Ldm, 2014; Pretorius 2014; Bayat, Louw and Rena, 2014). This scenario is puzzling as since 1994, numerous efforts have been made by the government and researchers alike towards understanding existing predicaments and providing solutions where applicable.

However, despite these efforts, the issue of learner underperformance in poor South African primary schools remains an on-going debate, with a seemingly unclear outlook in the near future (Pretorius, 2014; Bayat, et al., 2014). The existing circumstances are predominantly blamed on poverty, teacher quality and content knowledge, parental lack of education, and poor management skills of school principals (Anderson, Case and Lam, 2001; Yamauchi, 2011; Hoadley 2012; Spaull, 2013). This prevailing view of the causes of underperformance in poor schools has resulted in numerous efforts by the government over more than 20 years to reallocate the necessary resources to meet the needs of such schools, yet, despite this, the issue of learner underperformance in poor schools has not been addressed and moreover remains a cumbersome and contentious issue. This also raises the question of how effectively the democratic dispensation has been translated into benefits for poor school communities (Maarman, 2009).

In attempting to investigate these unanswered or unsatisfactorily answered questions, it is tempting to ask whether efforts made have been inadequate in scale, or whether the issues themselves have been poorly or incorrectly understood. Exploring the SPP through the lens of the CA can contribute towards answering the seemingly intricate question of the causes of learner underperformance in poor schools, and contribute to help to address the ongoing concerns of researchers, educationists and policy makers.

\section{Research aims}

The purpose of this paper is to demonstrate that although the SPP is ambitious and well intentioned, critical implementation and monitoring challenges negatively reconfigures the educational aspirations of primary school learners. The paper also aims to use the CA as its theoretical lens, despite its 
limitations, to show that although other exigencies exist, the SPP leads to certain unfreedoms on learners and teachers that intricately contribute to underperformance.

\section{Literature review}

The school progression policy in South Africa

Progression is referred to as "the movement of a learner from one grade to the next, excluding Grade $\mathrm{R}$, in spite of the learners not having complied with all the promotion requirements. Progression can be used to prevent a learner from being retained in a phase for a period exceeding four years. .."

(Department of Basic Education, 2011, p.xi). Although specific requirements are provided to guide learner promotion, the SPP is meant to ensure that, apart from spending a maximum of four years in a phase; learners are able to progress with their age cohort. The policy in this aspect stipulates that, since such learners are likely to repeat the new grade, they be given the necessary support to assist them to progress to the next grade, with the intention of promoting learner dignity, self-esteem and the need to encourage socialisation by age (Department of Basic Education, 2012).

The SPP is regarded as one of South Africa's key transformation vehicles within the education sector, taking into consideration the disadvantaged nature of poor schools as many are a product of " 40 years of inferior education. .." (Hartley, 2006, p.98). The critical issues resonating from the circumstances of poor schools as a consequence of historically inferior education are learner underperformance, and a high dropout rate. To offset the existent inequality within the educational sector, and at the same time maintain equity, quality and learner retention rates, the SPP is employed as a key tool to give learners the necessary support they require in order to achieve these objectives. The SPP is thus regarded as one of those policies or constructs that have contributed to unequal educational opportunities in South Africa (Maarman, 2009), mainly due to poor implementation and the lack of monitoring and evaluation.

Since a learner is only allowed to repeat a grade once in each phase, the learner is liable for promotion once he or she has already repeated a grade in a phase. In effect, the policy ensures that, a learner is given the opportunity to 
progress with the age cohort. In this circumstance, "the system is not able to prevent promotion to the next grade or phase even if she/he does not fulfil the educational requirements to be promoted" (Hartley, 2006, p.100). The assumption is that, however, the learner will be assisted to acquire the necessary content knowledge that he or she lacks in the new grade, in order to assist that learner to cope in the current grade, as well as, to progress to the next grade (Department of Basic Education, 2012). This approach is assumed apart from restoring learner dignity and self-esteem, it contributes to achieve South Africa's Millennium Development Goal (MDG) of ensuring that all children complete primary education despite their age (Statistics South Africa, 2013). However, it raises many theoretical and practical concerns in terms of learners' wellbeing, abilities, opportunities and logistical support during the teaching and learning process, the availability of support systems in place to facilitate the coping process for learners, and the resultant performance.

Despite existing uncertainties, learner progression within the South African context is viewed as a good systemic indicator of quality education (Hartley, 2006). As such, automatic progression is preferred within the South African context considering that retention is regarded as being synonymous with learner dropout (Branson, Hofmeyr and Lam, 2013; Hartley, 2006). Hartley (2006), though arguing for learner progression, acknowledges the challenges that accompany learners that are promoted without acquiring the necessary content knowledge required for the new grades.

\section{Progression and performance debates}

Debates around learner progression, retention and performance are on-going, contentious and contradictory. Jimerson and Renshaw (2012) argue that neither retention nor automatic promotion have the potential to fully assist learners at risk, nor provide satisfactory answers to learner challenges and underperformance, because both approaches harbour a host of disadvantages. Educationists, researchers, and policy makers around the world struggle to fully explain learner underperformance. In the case of Q-1 schools in South Africa persistent learner underperformance is particularly puzzling, considering increasing government efforts in terms of resource allocation, and the introduction of policies such as the SPP aimed at promoting access, equity and quality education (Hartley, 2006). 
The literature shows that these debates advocate either grade repetition or automatic promotion (Scott and Ames, 1969; Alexander, Entwise and Dauber, 2003). For example, Scott et al. (1969) argue that, grade repetition has a noble role to play in the child's development and ability to perform better, because they repeat a grade and have the opportunity to acquire more knowledge. Scott et al. (1969, p.434) added that repeating means going at a slower rate, a process that reduces the pressure on the learner and thus makes things easier for a learner who is having difficulty. Scott et al. (1969), however, argue that the process does not ultimately provide a cure for other school problems that the learners might be having. Alexander et al. (2003) investigated the advantages and disadvantages of both learners that are automatically progressed and those that are allowed to repeat, in the context of existing support structures both in the new and current grades respectively. They conclude that what matters most is the kind of support structures in place, because the lack of a proper coping process and structures both for those that are allowed to repeat and those that are promoted could result in learners performing worse than they were at the beginning of the year. This view is supported by Jimerson, Carlson, Rotert, Egeland and Sroufe (1997) who argue that the kinds of mechanisms in place to assist retained learners may result in retained learners performing worse than if automatically promoted. Furthermore, Pagani, Tremblay, Vitaro, Boulerice and McDuff (2001) argue that there are possibilities for certain characteristics embedded in learners to persist or even become worse than if they are automatically promoted or promoted needing assistance. Picklo and Christenson (2005) maintain that promoting learners that do not possess the required academic requirements presents such learners with challenges, because they are likely to struggle to cope with the workload of the new grades, a scenario they consider also frustrating for teachers who are exposed to unprepared learners within their classrooms.

Conversely, Jimerson, et al. (1997) hold the view that the negative effects of retention outweigh social promotion and therefore assume that promoting learners, even if they do not acquire the necessary academic requirements, is preferable. Jimerson et al. (1997), however, fail to suggest strategies that can be employed to guarantee coping in the new grades for learners that are automatically promoted. 


\section{The capability approach and education}

The Capability Approach (CA), a central concept in the works of Amartya Sen, is used as a theoretical lens to assess the efficacy of the SPP because its principles are embedded within the circumstances of Q-1 schools. The human well-being factor that underpins the CA is closely, though not directly, linked with education, which, however, still needs to be properly exploited by researchers within this domain (Saito, 2003). In recent years, education, as a discipline has increased its use of the CA as a framework for theorising, implementing and evaluating social policy as a matter of social justice, based on the CA's commitment to social justice, human wellbeing, freedom, development and human agency, and in its practical emphasis on what people are actually able to do and to be (Walker, 2006; Walker and Unterhalter, 2007). This is justified by the fact that the CA focuses on what people are able to do and to be, rather than on their material possessions (Sen, 1992). This justifies the quality of life and wellbeing of individuals as the underpinning of the CA. Amartya Sen (1992), in outlining his CA, considers freedoms and unfreedoms as primary elements in determining achievement, and these are applicable in the assessment of the circumstances and experiences of Q-1 primary schools in relation to the SPP. Sen (1992) postulates that, even where equal resources are provided, and barriers or constraints to achievements exist, there are possibilities of variations in outcomes.

The CA is underpinned by constructs such as; Capabilities, Functionings, Freedoms and Unfreedoms. According to Sen (2005, p.154), "A capability refers to a combination of functionings from which the person can choose one combination". In the context of this paper functionings relate to human fulfilment; that is, the valuable activities and states that make up a person's well-being. It can be summarised as what a person actually manages to do or to be. In the view of Sen, a person's wellbeing in society is thus judged by a "person's capability to do things he or she has reason to value" (Sen, 2009, p.231). Sen thus lays emphasis on the fact that the CA is controlled by two variables which are the means to achieving what a person desires, and the ends that reflect the actual opportunities accrued after a particular combination. In this paper learner performance is regarded as an end in the understanding of human wellbeing, and the SPP as a means to achieving that end, since the CA focuses more on opportunities available to fulfilling ends rather than the means to achieving these. What an individual is thus able to achieve or not achieve is determined by existing freedoms and unfreedoms. 
In Sen's view freedoms are crucial in the understanding of human wellbeing because the actual freedoms we have to choose the kind of life we value do undoubtedly influence the ends (Sen, 2009). Here, Sen (2009) identifies two kinds of freedoms; opportunity freedom and process freedom. Opportunity freedom articulates the opportunity one has to pursue valued objectives in order to promote valued ends. Here the inability of learners to receive the necessary support as indicated in the SPP in order to perform means that they were missing out on their opportunity freedom. Process freedom on the other hand ensures that one is not "being forced into some state because of the constraints imposed by others" (Sen, 2009, p.228). In this paper the SPP is looked at from the process approach of freedom, considering the possibility of alternative learner outcomes if other methods other than the SPP were used, for example allowing learners to repeat a grade to gain more content knowledge before progressing to a new grade. The CA thus "proposes a serious departure from concentrating on the means of living to the actual opportunities of living" (Sen, 2009, p. 233).

This paper argues that there is a need to apply the CA as a means of understanding the underlying reasons for the nature of learner performance in South African primary schools, by investigating the real freedoms and unfreedoms embedded within the SPP. Such an interrogation would incorporate Sen's view that people and communities differ in many ways, and as such, inequalities peculiar to them may positively or negatively influence the institution's or individuals' freedoms to achieve irrespective of the amount of resources (Sen, 1992). Therefore, the SPP cannot in itself determine performance, but rather how the various individual schools implement the policy to attain certain functionings (Sen, 1985 and 1999). According to the CA, the ability of schools to implement the policy to achieve set goals is influenced by both internal and external factors (Sen, 1985). The $\mathrm{CA}$ is thus seen as a broad, normative framework for the evaluation and assessment of individual well-being and social arrangements, as well as the design of policies, and proposals about social change (Sen, 1989). Therefore, interrogating the existing SPP within the context of poor primary schools using the $\mathrm{CA}$ is considered a valid contribution to the ongoing debate concerning learner progression, retention and performance.

The key conceptual shift of the CA is to challenge the common assumption that resources equal achievement. It argues that, in the case of education, individuals or institutions/schools should not be assessed based on the amount of resources at their disposal without considering the salient but silent 
variables (internal and external characteristics) that influence their abilities to achieve what they value in life relating to education. According to the CA, these internal and external features are considered to differ within and between spaces, based on the assumption that every person or institution/school is unique, and thus should be assessed based on the characteristics of individual spaces and capabilities. This view should provoke reflection on how human diversity impacts on assessment of equality and inequality in the domain of Q-1 primary schools. Sen (1992) argues that diversity enables people or schools to progress differently even in circumstances where they have the same amounts of primary goods. Sen (1992, p.xi), in reemphasising the importance of uniqueness (human diversity) in influencing achievement, argues that, it is not advisable to assess or compare two institutions or persons based on the premise that "all men are created equal", while ignoring the important, salient variables that create the possibilities of other inequalities within and between spaces. Such variations in school settings are considered to significantly influence the implementation of the SPP and consequently influencing learner performance within schools.

The SPP is thus interrogated vigorously within this milieu using the CA, to better understand existing learner performance challenges within school spaces. This is aimed at providing new insights into how we think about what people do, why they do what they do, and why they succeed or fail to succeed (Terzi, 2005). In this context, the paper investigates the SPP in relation to the on-going underperformance within a particular poor school community, using the $\mathrm{CA}$ as a preferred theoretical lens.

\section{Research methodology}

To address the research aims, a study was undertaken in three Q-1 primary schools in an informal settlement in Cape Town. A literature review was undertaken to understand the various dynamics, features, debates, and contestations surrounding learner underperformance in the selected primary schools, as well as, progression debates. For research purposes, these schools are classified as schools A, B and C. A qualitative study was conducted between April and September 2012, and February and March 2013, to understand the intricacies surrounding learner underperformance in the three selected Q-1 primary schools. 
These schools have many obvious similarities in terms of learner background, and being located in a community with similar socioeconomic status (SES), and amounts of support received from the government in terms of school resources, considering that they are all Q-1 schools. Four teachers, twenty learners from each of the schools, and the principals were part of the investigation. Mainly Grade 7 learners investigated were part of a cohort that entered Grade R in 2005 to 2012 when they were in Grade 7. However, for the purpose of this paper only data collected through the analysis of learner schedules/report cards as well as, questionnaires and interviews with teachers and school principals was extensively used.

Interviews were conducted with principals, while 4 teachers from each of the schools participated in focus group interviews. Questionnaire questions were administered to teachers and the principals based on their varying responsibilities. The questions asked to principals were centred on their role to enhance and facilitate the conversion of existing school resources into learner performance, especially in terms of the SPP. This was also intended to understand the challenges and unfreedoms principals encounter in implementing the SPP, taking into consideration the fact that poverty on its own within this community do bring challenges that negatively affect learner performance. Questions asked to teachers covered areas such as curriculum implementation, classroom management, unfreedoms encountered in the course of implementing the curriculum, and classroom dynamics in relation to the SPP. Learner schedules were also scrutinised to understand the nature of learner progression, the implication of the SPP on learner performance in the new grades, and unfreedoms inherent within the system, in terms of large classes, ignorance of the existence of the policy and its demands, as well as, monitoring and evaluation. Information was thus obtained on how and why learners were progressed, and how they performed in the new grades, taking into consideration the obligation to receive support as stipulated by the SPP (see table 1).

The data obtained through interview were captured through audio recording, transcribed and analysed to obtain a picture of how the implementation of the SPP impacted on learner experiences and performance. Interview data were cross-checked and compared with data obtained from learner schedules for validity and reliability. 


\section{Discussion}

Structure of the school progression policy

The SPP provides that, in circumstances where learners display a lack of preparedness for the next grade, but qualify in terms of age to progress with the appropriate age cohort, there is a need to specifically assess them to determine the level of support they would require in the next grade if progressed (Department of Basic Education, 2011). The policy was thus designed to ensure that learner needs are clearly indicated in the report cards/schedules as 'needing support'; including the appropriate details to ensure that the teacher in the new grade adequately comprehends the nature and extent of learner needs. However, in the schools surveyed the nature of reporting in the schedules in terms of learner needs is in itself vague, because the particular section of the subject in which the learners need support is not specified, and how, when, and who will provide the necessary support is also not provided for.

The policy designers expected that various schools put in place their own unique workable strategies to implement the demands of the policy in order to assist learners in need. In essence, the policy theoretically expected that principals through the Heads of Departments (HoDs) monitor and evaluate teacher abilities and efforts in implementing the SPP (Hartley, 2006).

However, the lack of monitoring and evaluation by the Department resulted in the existence of a blanket policy whereby schools, in the case of those surveyed; either could not correctly interpret the policy aims and objectives, ignored the policy entirely or merely implemented these policy directives in their own unique and seemingly contradictory ways, and thus impeding learner freedoms.

Implementation of the school progression policy

The SPP in poor schools is beset by a series of challenges and implications for learner performance due to its lack of a clear cut structure and implementation plan. Although the policy theoretically designates that learners promoted based on their age and the number of times they may have repeated a grade are given the necessary support to help them cope with the challenges of the new grades, how and when that support should be given and by whom 
remains unclear, often leading to misinterpretation and laxity on the part of the teachers in policy implementation. The policy also does not clearly indicate how the implementation chain works, in terms of responsibilities, monitoring and evaluation of the functionality of the policy in individual schools.

Although monitoring and evaluation of the SPP in schools on the part of the principals ought to be a continuous and developmental process (Hartley, 2006), the principals in this study reasoned that monitoring and evaluation of teachers in relation to the implementation of the SPP and other aspects of the curriculum remained the prerogative of the HoDs. This in fact echoes the lack of standardised strategies, and monitoring and evaluation mechanisms on the part of the DoE, the principals, and HoDs. Clearly, this scenario indicates that teachers are left on their own to implement the policy in their own unique ways and at their own leisure, thus the adoption of conflicting and contradictory approaches by individual teachers. Since there was no official 'catch-up' programmes in the schools that rendered the 'necessary support' specified by the policy, no clear cut directives on how information provided on learner reports cards ought to be transmitted, and used in the classroom, teachers thought and reacted varyingly towards policy imperatives. The sheer number of learners needing assistance, together with the large class sizes, compelled some teachers to abandon the idea of assisting learners on an individual basis, irrespective of how urgent and/or profound those needs were. Others were in fact unaware of the imperatives of the policy, and as such ignored its existence and requirements, and often conducted their lessons as usual without taking into consideration academically disadvantaged learners who needed special support. Teachers, who for diverse reasons were unable to assist the needy learners in terms of the policy directives, ended up lowering standards for all learners in their class in an attempt to assist weak learners to catch up, and in the end not completing the syllabus. The principal of school B indicated that educators struggle to complete problems carried over from the previous grades, before starting with the programme for the current grade, often setting in motion a backward trend that at times leads to retrogression. Also, educators passionate about learner ability to understand focus on bringing weak learners to speed and in the end unconsciously ignore the syllabus that has to be completed, and the standards that has to be maintained.

This clearly leads to learners being overwhelmed with unfreedoms in the new grades (see table 1) due to the lack of preparedness and inadequate coping 
resources in the new grades as enshrined in the aims and objectives of the SPP, and as expected by the Department of Basic Education (DBE) (Hartley, 2006). An educator lamented that, due to the promotion of academically unprepared learners, some kids in Grade 7 have the mind-set of Grade 4 learners. Without a proper coping process, this dilemma persists and deprives learners of opportunities to learn and chances to perform better.

In the schools surveyed, this dilemma can be attributed to the lack of collaboration, and a breakdown in communication between the teachers themselves, between teachers and HoDs, between HoDs and principals, and between principals and the DBE, thus limiting learners' freedoms to learn. This is because learners were deprived of the opportunity to learn what they ought to learn in order to become what they desire to be. In these schools, teachers and principals perceived responsibilities and performed functions their own way despite specifications by the DBE for the development of teachers, and school management personnel and departmental support for personnel since it is regarded as an important facet of achieving set goals (Department of Education, 2002). Some teachers in these schools as a consequence of a breakdown in communication, and the lack of monitoring and evaluation, ignored the entire process on the grounds that they ought to be told at the beginning of each school year the number of learners in their classes with needs, and the specific kinds of needs, while in the view of the principals it is the duty of the teachers to check learner schedules that are readily available for that purpose. However, there were possibilities of teacher effort being dampened by the nature of information contained in the report cards, since most of the information was not explanatory enough as required.

Another challenge inherent in the implementation of the SPP in the schools surveyed relates to the nature of information contained in the learner report cards/schedules, which did not in fact provide a proper description of the kind of assistance required by each and every learner, and in every subject. Learner report cards/schedules conveyed inadequate information or vague comments such as, 'The learner needs support in all learning areas', 'Needs support in English and Mathematics', 'Needs support in Mathematics and Languages', but did not directly, or clearly indicate which section of the learning area/subject the learner was struggling to cope with. This in a way prevented teachers from giving learners the deserved support, thus impacting on their freedoms to learn and pass. Despite the fact that teachers were in theory expected to provide a list of learners who they considered needed assistance, with a detailed description of the kind of needs they required for easy 
identification and support, that was never the case. As such, many teachers in the schools surveyed interpreted the policy in their own unique and inconsistent ways, and attended to it at their own leisure, although some of them ignored the entire process based on the inconsistent and contradictory processes involved. One of the teachers affirmed that she did not bother to look at learner schedules to know those that came to her class needing assistance, but was able to identify some of them in the course of the year.

In addition, in the schools surveyed, emphasis was placed primarily on languages and mathematics, while ignoring other subject learning areas, even if learners struggled to cope in these areas. This scenario made it difficult to identify the particular needs of the learners, thus creating spaces for confusion, inconsistency, and misinterpretation. This in effect limited learner freedoms to acquire the assistance they deserved, and in turn dampened the necessary abilities for coping in the new grades. Table 1 below shows three learners that were promoted from Grade 6 to 7 in 2011 needing assistance, but struggled to cope and were unable to gain promotion to High School.

Table 1: Learner progression decision at the end of $4^{\text {th }}$ term in Grade 7 in 2012 for selected learners in school A

\begin{tabular}{|l|l|l|l|l|l|l|l|l|l|l|}
\hline No of Subjects & $\mathbf{1}$ & $\mathbf{2}$ & $\mathbf{3}$ & $\mathbf{4}$ & $\mathbf{5}$ & $\mathbf{6}$ & $\mathbf{7}$ & $\mathbf{8}$ & $\mathbf{9}$ & Progression decision \\
\hline $\begin{array}{l}\text { Learner A's final } \\
\text { subject codes at the } \\
\text { end of fourth term }\end{array}$ & 3 & 2 & 1 & 2 & 2 & 3 & 4 & 2 & 3 & Not Ready to Progress (NRP) \\
\hline $\begin{array}{l}\text { Learner B's final } \\
\text { subject codes at the } \\
\text { end of fourth term }\end{array}$ & 3 & 1 & 2 & 3 & 1 & 2 & 2 & 3 & 2 & Not Ready to Progress (NRP) \\
\hline $\begin{array}{l}\text { Learner C's final } \\
\text { subject codes at the } \\
\text { end of fourth term }\end{array}$ & 3 & 2 & 1 & 2 & 1 & 2 & 1 & 1 & 2 & Not Ready to Progress (NRP) \\
\hline
\end{tabular}

The inconsistencies embedded in the SPP create an awkward situation. The principal of school B indicated that teachers misinterpreted the policy and assumed that they have the obligation to repeat the entire syllabus to enable struggling learners to catch up; a process many educators in the schools surveyed considered boring, time consuming, and futile, especially for those learners that genuinely earned their promotion and needed to acquire new knowledge. Thus, the nature of the SPP and the limited efforts of the teachers 
prevented learners from receiving the necessary support, further deepening existing unfreedoms.

The SPP has two tenets that gave learners dual options to be promoted, even if they lack the required academic knowledge: the age cohort, and the fact that they can only repeat a grade once in each phase, resulting in a rise in the number of learners promoted needing assistance, especially in poor schools. In the schools surveyed, the number of learners needing individual support, as well as the class size, in essence compelled teachers to abandon the idea of assisting learners individually, irrespective of how urgent or profound their needs were (see table 2). The principal of school A perceived that giving assistance to such academically challenged learners was similar to 'chasing a shadow'.

Table 2: Number of learners promoted in school A needing assistance from Grade 3 to 4 in 2008

\begin{tabular}{|l|c|c|c|c|c|}
\hline & Grade 3A & Grade 3B & Grade 3C & Grade 3D & Total \\
\hline $\begin{array}{l}\text { Number of learners in } \\
\text { class }\end{array}$ & 43 & 41 & 44 & 40 & 168 \\
\hline Ready to progress & 22 & 28 & 20 & 26 & 96 \\
\hline $\begin{array}{l}\text { Ready to progress with } \\
\text { support }\end{array}$ & 21 & 13 & 24 & 14 & 72 \\
\hline Not ready to progress & 2 & 4 & 8 & 1 & 15 \\
\hline
\end{tabular}

This is compounded by the fact that the kind of support needed by such learners to meet the required content knowledge went beyond the curriculum (Bojuwoye, Moletsane, Stofile, Moolla and Sylvester, 2014). As such, these teachers and principals saw the policy as 'a necessary evil' because of the effects of unfreedoms that were accumulated on the part of the teachers, needy learners, and those that were promoted genuinely. One of the teachers commented on the impossibility of rendering individual assistance to the numbers of learners needing the 'necessary support' stipulated by the policy:

The number of learners in each class makes it impossible to assist those in need. I say so because, too many learners need that individual support that we as teachers cannot give to all of them. Individual 
assistance will mean extra teaching time and resources that we don't have, especially because the needs of some of the learners are very deep. Teachers do try to give general assistance to learners, but not focusing on the actual individual needs that are on the report cards, although at one point that could be crucial to the way they perform.

Since teachers found the demands of the SPP overwhelming, they devised different methods to cope that included repeating a chunk of the syllabus of the previous grade as a means of bringing needy learners up to speed. The effect was that those learners that progressed normally and needed new content knowledge were deprived of that freedom, and also, the probability of not completing the syllabus for the current grade by the end of the school year increased.

\section{Effects of the progression policy on learner aspirations}

The SPP in essence overburdened already challenged learners by pushing them into new grades where bigger challenges awaited them, especially in an environment which played an important role in their motivation, aspirations, learning opportunities and performance. Statistics obtained from school A in 2012 shows that learners who were promoted from Grade 6 to 7 needing support struggled to achieve certain functionings. Results in the fourth term indicates that many of these learners were hovering between ratings/codes of 1-3 in all subject areas, with code 1 representing not achieved, code 2 indicating elementary achievement and code 3 moderate achievement. All three categories represent achievements below 50\%. Motala, Dieltiens and Sayed (2009) argue that learners who are not in the correct age range for their grade are likely to struggle with their work and may be more vulnerable to dropping out. Learners in the schools surveyed struggled because they were not being given the individual and special support they required in terms of the knowledge and the academic requirements they had failed to acquire in previous grades as required by the DBE (Hartley, 2006). This was exacerbated by the fact that teachers struggled with the dilemma of assisting needy learners with content knowledge of previous grades, while risking neglecting to complete the syllabus of the current grade in the end disadvantaging all learners in their classroom including those that were promoted genuinely. In fact, the existing structural setup of the SPP indicates that these teachers are under no strict obligation to provide this support. 
According to the teachers, learners who were legitimately promoted often failed, not because they deserved to, but because they were unfairly denied the opportunities to acquire adequate content knowledge in the new grades. In some instances the time which should have been spent on covering the syllabus of the current grade was used repeating the content of the previous grade with the aim of bringing the weak learners promoted for reasons other than academic achievement up to speed, resulting in incremental unfreedoms for everyone in the classroom. The principal of school B indicated that due to this dilemma, teachers were obliged to either use up more time for revision or taught at a slower pace because needy learners in the disadvantaged schools were often overwhelmed with the workload of the new grade that was often beyond their capabilities, thus plunging the entire class into a circle of failure. In his view, standards were being lowered for all learners in the classroom in an attempt to accommodate the needy learners.

It was clear in the schools surveyed that lowering standards in the course of teaching and assessment with the intention to integrate the needy learners was no guarantee of an improvement in learner levels of understanding and in turn learner performance, because these learners were in fact being conditioned to be less competitive. According to the principal of school C, learners performed well in class tests and examinations because teachers set questions based on the limited syllabus covered, but failed in competitive examinations that were set following the official syllabus. In fact, these learners were being trapped in a cycle of underperformance, and often remained at the same level or in some cases regressed. For example, out of a total of approximately 142 learners who were in Grade 6 in 2011 in school A, 130 of them progressed to Grade 7 needing assistance in one or more subject areas. 91 of these learners partially achieved in more than 5 learning areas out of 9 . Out of this number 18 of them partially achieved or did not achieve in all 9 learning areas, but were promoted to Grade 7 needing support. In effect, 91 learners in Grades A, $\mathrm{B} \& \mathrm{C}$ failed to obtain an average of more than $50 \%$ in any of the 9 learning areas in the four terms combined, but were promoted to Grade 7 . According to available records, out of 40 learners in Grade 7A, who completed the $4^{\text {th }}$ term successfully in 2012, only one learner progressed to high school without needing support during any of the school terms or subject areas, while the rest needed support in at least one or more subject areas. Statistics obtained from the school records revealed that many of these learners obtained a series of $2 \mathrm{~s}$ (elementary achievement) and $3 \mathrm{~s}$ (moderate achievement) but were promoted to high school where the tenet of the SPP is not applicable. In essence, the policy formalises and perpetuates learner incompetency within the system, 
and increases the probability of learners not achieving the required content knowledge, especially in poor school communities. It also creates room for numerous unfreedoms for learners who are unable to achieve the required or expected standards at the end of each year.

The leniency afforded by the policy encouraged the passive and demotivated attitude exhibited by learners, because they knew that, irrespective of their status or results, progression was guaranteed based on reasons other than regular attendance or satisfactory results. Although the SPP in fact condemns learner absenteeism, it contradicts itself with the age variable, and the stipulated number of years to be spent in each phase, giving undeserving learners a chance to progress while they accumulate additional unfreedoms as they do so.

\section{Conclusion}

The SPP, though a noble strategy aimed at ensuring access to education, maintaining a reasonable retention rate, and achieving government's goal of equity and quality education, is a debatable policy considering its actual contribution to learner experiences, abilities and freedoms in the classroom, particularly in poor school communities. The lack of clear cut structures and implementation strategies, and the policy's over-reliance on abstract rather than practical directives, creates numerous unfreedoms for learners and teachers. In its process the SPP ignores the opportunities available to the learners themselves, creating a tension between its intentions and its actual implementation and outcomes on learners in individual schools located in a variety of contexts. Although the policy relies on 'learner support' to be provided by teachers in the new grades, it fails to take into consideration issues such as the coping process required by learners, variances in the degree of learner needs and challenges, and the number of learners needing support in each grade at a particular time. It also fails to consider teacher capability to offer the required support, and also its actual impact on the teaching and learning process in terms of time needed to assist needy learners in relation to the aspirations of fellow learners that progressed genuinely. Here the policy focuses more on the number of learners that are promoted to the next grade, while ignoring the circumstances under which learners have to acquire the content knowledge required for survival in these new grades. This in effect incrementally reinforces and perpetuates learner challenges since inherent in 
the policy is the potential for learners to accumulate unfreedoms as they progress through the various grades based on age and the number of times they repeat a grade, rather than on academic achievement. Although poverty and other exigencies undeniably introduce challenges to school performance, unfreedoms enhanced by the SPP no doubt illustrate the complexities inherent in the nature of schooling in poor communities (Maarman, 2009).

\section{References}

Alexander, K.L., Entwise, D.R., and Dauber, S.L. (2003). On the success of failure: A reassessment of the primary school grades, $2^{\text {nd }}$ Edition. Cambridge: Cambridge University Press.

Anderson, K.G., Case, A., and Lam, D. (2001). Causes and consequences of schooling outcomes in South Africa: Evidence from survey data. Social Dynamics: A Journal of African Studies, 27(1), 37-59.

Bayat, A., Louw, W., and Rena, R. (2014). The impact of socio-economic factors on the performance of selected high school learners in the Western Cape Province, South Africa. Journal of Human Ecology, 45 (3),183-196.

Bojuwoye, O., Moletsane, M., Stofile, S., Moolla, N., and Sylvester, F. (2014). Learners' experiences of learning support in selected Western Cape schools. South African Journal of Education, 34(1).

Branson, N., Hofmeyr, C., and Lam, D. (2013). Progress through school and the determinants of school dropout in South Africa. Southern Africa Labour and Development Research Unit UCT. Working Paper Series, Number 100. Available at http://hdl.handle.net/11090/616. Accessed 26 May 2015.

Chisholm, L. (2004). The quality of primary education in South Africa. Background Paper Prepared for UNESCO Education for All Global Monitoring Report. Available at http://unesdoc.unesco.org/images/0014/001466/146636e.pdf. Accessed 10 October 2012. 
Crouch, L. and Mabogoane, T. (2001). No magic bullets, just tracer bullets: The role of learning resources, social advantage, and education management in improving the performance of South African schools. Social Dynamics, 27(1), 60-78.

Department of Education. (2002). Revised National Curriculum Statement Grades R-9 (Schools). Available at www.education.gov.za/LinkClick.aspx?fileticket=WJoXaOgvys4\%3D\& amp;tabid. 5 June 2015.

Department of Education. (2008). Ministerial committee on learner retention in the South African schooling system. Available at http://resep.sun.ac.za/wp-content/uploads/2012/07/DOe-2008-Learner-R etention-report.pdf. 2 June 2015.

Department of Basic Education. (2011). National Protocol for Assessment Grades $R-12$. Available at http://www.education.gov.za/Portals/0/Documents/Legislation/Gov\%20 Not/36041 28-12 BasicEducation.pdf. Accessed 3 June 2015.

Department of Basic Education. 2012. The South African Schools Act, 1996 (Act No. 84 of 1996): Approval of the Regulations Pertaining to the National Curriculum Statement Grades R-12. Vol. 570, No. 9886, Pretoria.

Hartley, Z. (2006). Setting a strong foundation in literacy and numeracy up to Grade 6 through a comprehensive GET strategy. Education Planning: Western Cape Education Department, pp.95-104. Available at http://wced.school.za/home/projects/hcds/strategy/documents/Reflection s1 Chapter7.pdf. Accessed 23 November 2013.

Hoadley, U. (2012). What do we know about teaching and learning in South African primary schools? Education as Change, 16(2),187-202.

Itumeleng, S. and Ldm, L. (2014). The role of school management teams in underperforming schools: A matter of values. Mediterranean Journal of Social Sciences, 5(3), 475-483. 
Jimerson S., Carlson, E., Rotert, M., Egeland, B., and Sroufe, L.A. (1997). A prospective, longitudinal study of the correlates and consequences of early grade retention. Journal of School Psychology, 35(1), 3-25.

Jimerson, S.R. and Renshaw, T.L. (2012). Retention and social promotion. Principal Leadership, pp. 12-16. Available at https://www.nasponline.org/Documents/.../NASSP Grade Retention S ept_2012.pdf. Accessed 2 May 2015.

Maarman, R.F. (2009). Manifestations of 'capability poverty'with learners attending informal settlement schools. South African Journal of Education, 29(3), 317-331.

Modisaotsile, B.M. (2012). The falling standard of basic education in South Africa. African Institute of South Africa: Policy Brief, No. 72. Available at

http://www.ai.org.za/wp-content/uploads/downloads/2012/03/No.-72.Th e-Failing-Standard-of-Basic-Education-in-South-Africa1.pdf. Accessed 20 May 2013.

Motala, S., Dieltiens, V. and Sayed, Y. (2009). Physical access to schooling in South Africa: Mapping dropout, repetition and age-grade progression in two districts. Comparative Education, 45(2), 251-263.

Pagani, L., Tremblay, R., Vitaro, F., Boulerice, B., and McDuff, P. (2001). Effects of grade retention on academic performance and behavioral development. Development Psychopathology, 13 (2), 297-315.

Picklo, D.M. and Christenson, S.L. (2005). Alternatives to retention and social promotion: The availability of instructional options. Remedial and Special Education, 26(5), 258-268.

Pretorius, S.G. (2014). An education system's perspective on turning around South Africa's dysfunctional schools. Mediterranean Journal of Social Sciences, 5(15), 348-358.

Saito, M. (2003). Amartya Sen's capability approach to education: A critical exploration. Journal of Philosophy of Education, 37(1), 17-33. 
Scott, B.A. and Ames, L.B. (1969). Improved academic, personal, and social adjustment in selected primary-school repeaters. The Elementary School Journal, 69(8), 431-439.

Sen, A.K. (1985). Commodities and capabilities. The Netherlands: Elsevier Science Publishers B.V.

Sen, A.K. (1989). Development as capability expansion. Journal of Development Planning. Available at http://morgana.unimore.it/Picchio Antonella/Sviluppo\%20umano/svilu pp\%20umano/Sen\%20development.pdf. Accessed 27 August 2010.

Sen, A.K. (1992). Inequality re-examined. New York: Clarendon Press.

Sen, A.K. (1999). Developments as freedom. Great Britain: Oxford University Press.

Sen, A.K. (2005). Human rights and capabilities. Journal of Human Development, 6(2).

Sen, A.K. (2009). The idea of justice. London: Allen Lane.

Spaull, N. (2013). South Africa's education crisis: The quality of education in South Africa 1994-2011. Report Commissioned by Center for Development and Enterprise. Available at http://www.section27.org.za/wp-content/uploads/2013/10/Spaull-2013CDE-report-South-Africas-Education-Crisis.pdf. Accessed 13 January 2014.

Spaull, N. (2014). Matric is failing SA's lost children. Mail \& Guardian. Available at http://mg.co.za/article/2014-01-09-matric-is-failing-sas-lost-children. Accessed 25 February 2015.

Statistics South Africa. (2013). Millennium Development Goals - Goal 2: Achieve Universal Primary education. Statistics South Africa, Pretoria. Available at http://www.statssa.gov.za/MDG/2010_MDG_GOAL_2_ACHIEVE_UN IVERSAL_PRIMARY EDUCATION.pdf. Accessed 5 May 2015. 
Taylor, S., Van der Berg, S., and Burger, R. (2012). Low quality education as a poverty trap in South Africa. Research Paper, University of Stellenbosch. Available at http://hdl.handle.net/123456789/795. Accessed 27 July 2013.

Taylor, N., Fleisch, B., and Shindler, J. (2008). Changes in education since 1994. Available at

http://www.jet.org.za/publications/research/Taylor\%20Fleisch\%20Shind ler\%20Changes $\% 20 \mathrm{in} \% 20$ Education $\% 2015 \% 20$ year $\% 20$ review.pdf. Accessed 13 August 2013.

Terzi, L. (2005). Beyond the dilemma of difference: The xapability approach and special education needs. Journal of Philosophy of Education, 39(3), 443-459.

Van der Berg, S. (2006). Lesson learnt from SACMEQII: South African student performance in regional context. Paper to the Conference on Investment Choices for Education in Africa, September 2006. Available at http://www.ekon.sun.ac.za/wpapers/2007/wp162007/wp-16-2007.pdf. Accessed 12 February 2012.

Walker, M. (2006). Towards a capability-based theory of social justice for education. Journal of Education Policy, 21(2), 163-185.

Walker, M. and Unterhalter, E. (2007). Amartya Sen's capability approach and social justice in education. Palgrave: Macmillan.

Yamauchi, F. (2011). School quality, clustering and government subsidy in post-apartheid South Africa. Economics of Education Review, 30 (1), 146-156.

Paul Munje

Rouaan Maarman

University of the Western Cape

munjepaul@gmail.com

rmaarman@uwc.ac.za 